\title{
Self-Rated Health and Long-Term Prognosis of Depression
}

\author{
Gilles Ambresin, $M D^{1}$ \\ Patty Chondros, $\mathrm{PbD}^{1}$ \\ Cbristopher Dowrick, $M D^{2}$ \\ Helen Herrman, $M D^{3}$ \\ Jane M. Gunn, $P b D^{1}$ \\ ${ }^{1}$ General Practice and Primary Health Care \\ Academic Centre, The University of Mel- \\ bourne, Carlton, Australia \\ ${ }^{2}$ Primary Medical Care, University of Liver- \\ pool, Liverpool, England \\ ${ }^{3}$ Centre for Youth Mental Health, The Uni- \\ versity of Melbourne, Parkville, Melbourne, \\ Australia

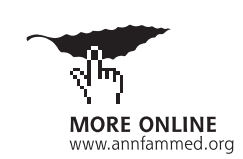

Conflicts of interest: none reported.

\author{
CORRESPONDING AUTHOR \\ Jane M. Gunn, PhD \\ General Practice and Primary Health Care \\ Academic Centre \\ The University of Melbourne \\ 200 Berkeley Street \\ Carlton, VIC 3053, Australia \\ j.gunn@unimelb.edu.au
}

\begin{abstract}
PURPOSE Indicators of prognosis should be considered to fully inform clinical decision making in the treatment of depression. This study examines whether self-rated health predicts long-term depression outcomes in primary care.
\end{abstract}

METHODS Our analysis was based on the first 5 years of a prospective 10-year cohort study underway since January 2005 conducted in 30 randomly selected Australian primary care practices. Participants were 789 adult patients with a history of depressive symptoms. Main outcome measures include risks, risk differences, and risk ratios of major depressive syndrome (MDS) on the Patient Health Questionnaire.

RESULTS Retention rates during the 5 years were 660 (84\%), 586 (74\%), 560 (71\%), 533 (68\%), and 517 (66\%). At baseline, MDS was present in $27 \%(95 \% \mathrm{Cl}$, 23\%-30\%). Cross-sectional analysis of baseline data showed participants reporting poor or fair self-rated health had greater odds of chronic illness, MDS, and lower socioeconomic status than those reporting good to excellent self-rated health. For participants rating their health as poor to fair compared with those rating it good to excellent, risk ratios of MDS were 2.10 (95\% Cl, 1.60-2.76), 2.38 (95\% $\mathrm{Cl}, 1.77-3.20), 2.22$ (95\% Cl, 1.70-2.89), 1.73 (95\% Cl, 1.30-2.28), and 2.15 (95\% $\mathrm{Cl}, 1.59-2.90)$ at $1,2,3,4$, and 5 years, after accounting for missing data using multiple imputation. After adjusting for age, sex, multimorbidity, and depression status and severity, self-rated health remained a predictor of MDS up to 5 years.

CONCLUSIONS Self-rated health offers family physicians an efficient and simple way to identify patients at risk of poor long-term depression outcomes and to inform therapeutic decision making.

Ann Fam Med 2014;57-65. doi:10.1370/afm.1562.

\section{INTRODUCTION}

$\mathrm{D}$ epression is the largest contributor to the burden of disease in high-income countries, and further increases are expected. ${ }^{1,2}$ Of those who seek professional help for depression, $80 \%$ turn to a primary care physician. ${ }^{3}$ The high prevalence of depressive symptoms in primary care patients highlights the crucial role of primary care in the detection and treatment of depression. ${ }^{4,5}$ In clinical practice understanding the prognosis for an individual is central to fully inform treatment decisions ${ }^{6}$ yet prognosis has received limited attention compared with therapeutic and etiological research. ${ }^{6,7}$ Validated prognostic indices provide estimates of the probability of an outcome for those with a particular condition ${ }^{7}$ and offer improved accuracy in prognostic assumptions that influence clinical decisions. ${ }^{8}$

The accuracy of family physicians in predicting the course of depression is described as fair, ${ }^{9}$ although as in other conditions it has been studied relatively little. Useful predictors of poor depression outcome in primary care have been identified in 3 main areas: individual characteristics (age, ${ }^{10}$ high neuroticism levels, ${ }^{11}$ perceived need for care, ${ }^{12}$ low mastery $\left.{ }^{13}\right)_{i}$ socioeconomic status (low education level, ${ }^{12}$ low income ${ }_{r}^{12}$ unemployment $\left.{ }^{12}\right)_{i}$ loneliness, ${ }^{12}$ low social support ${ }_{1}^{12,14}$ limitations of social activities due to health ${ }^{14}$; and health, both physical (medical comorbidity $_{1}^{11,12,14,15}$ chronic pain, ${ }^{11}$ daily smoking ${ }^{13}$ ) and mental (comorbid anxi- 
ety ${ }_{1}^{11,12,15}$ double depression, ${ }^{11}$ severity of depressive symptoms, ${ }_{11,12,14,16}$ somatic symptoms of depression, ${ }_{1}^{16}$ history of recurrent depression, ${ }^{15}$ remission status at 3 months, ${ }^{15}$ appropriate use of antidepressant medications, ${ }^{14}$ greater mental dysfunction ${ }^{16}$ ). Reliable assessment of the predictors listed above requires time and a multitude of validated instruments. In addition, physicians tend to prefer their clinical judgment when deciding about treatment. ${ }^{17}$ Many are ambivalent about questionnaire use $\mathrm{e}^{17,18}$ and may disregard such scores. ${ }^{19}$ Considering the everyday caseload of physicians, methods that take more than a few minutes have low acceptability in clinical practice, ${ }^{20-22}$ highlighting the need for practical, simple, reliable, and easily interpretable predictive tools ${ }^{23}$ that translate smoothly into daily clinical practice. ${ }^{24}$

Self-rated health may be a candidate for a simple and transportable prognostic index. It provides a singlequestion assessment of one's subjective health, encompassing physical functioning, as well as psychosocial aspects of health. ${ }^{25,26}$ Self-rated health has been used as a reliable, quick assessment for population health monitoring. ${ }^{27-29}$ Two large population studies and one large international multisite study in primary care found that self-rated health is associated with depression. . $^{40,31}$

Although there is sound literature on the association between depression and self-rated health, we lack prognostic studies investigating the link between it and depression outcomes over time. Two studies suggest that self-rated health may be an important predictor of poor depression outcome. ${ }^{32,33}$ An association between worse self-rated health and poor depression outcome 6 years later was noted in a study of 585 people with major depression drawn from a population-based longitudinal health survey. ${ }^{32}$ Selfrated health was not the main focus of the study and was not included in the final prognostic model. In the longitudinal US Cardiovascular Health Study of 5,888 Medicare recipients, self-rated health discriminated older adults most at risk for becoming or remaining depressed within a year. ${ }^{33}$ Nonetheless, it is unknown whether self-rated health can predict risk of long-term depression outcomes in primary care. We hypothesized, a priori, that people who rated their health as poor or fair at baseline would be at greater risk of poor depression outcomes over a 5-year follow-up.

\section{METHODS}

\section{Participants}

The participants were part of the Diagnosis, Management and Outcomes of Depression in Primary Care (diamond) study, an ongoing (2005-2016) prospective, longitudinal cohort study of patients with depressive symptoms based on the Centre for Epidemiologic Studies Depression Scale (CES-D $\geq 16)^{34}$ from 30 randomly selected Australian general practices. Study design, methods, and sample size calculations have been reported earlier. ${ }^{35}$ Participants completed annually a wide range of validated and study-specific measures that included demographic and socioeconomic characteristics, chronic conditions, major depression, and self-rated health.

\section{Measures}

\section{Patient Health Questionnaire}

The 9-item Patient Health Questionnaire (PHQ-9 ${ }^{36}$ ) is a widely used self-report measure of depression that is brief, easy to administer, and well validated. ${ }^{37}$ It consists of 9 criteria assessed over the last 2 weeks on which the diagnosis of the Diagnostic and Statistical Manual of Mental Disorders (Fourth Edition) (DSM-IV) depressive disorders is based. The PHQ-9 can establish provisional depressive disorder diagnoses or assess depression severity. ${ }^{38}$ The outcome was current major depressive syndrome (MDS) based on the PHQ-9 findings. Participants were classified as those experiencing MDS if they answered that 5 or more of the 9 depressive symptom criteria had been present at least "more than one-half the days" in the past 2 weeks and 1 of the symptoms was depressed mood or anhedonia, and those who were not. ${ }^{38}$ Depression severity was a continuous measure (range $=0$ to 27 ) calculated by summing PHQ-9 items.

\section{Self-Rated Health}

Health status during the preceding month was assessed using the general health question of the Short-Form 12 Health Questionnaire. ${ }^{39}$ Participants rated their health by answering the question: "In general, would you say your health is excellent, very good, good, fair, or poor." These responses were dichotomized into poor to fair (self-rating of fair or poor) and good to excellent (self-rating of good, very good, or excellent). This assessment has shown to be consistent with previously validated single-item measures of general subjective health, which have shown good reliability and validity. ${ }^{40}$

\section{Statistical Analysis}

Data analyses were conducted using Stata 12 (StataCorp LP). Data were summarized using counts and percentages. Statistical analyses were undertaken in 2 stages. The first stage sought to understand the components of self-rated health (cross-sectional analyses). Marginal logistic regression was used to examine the association between self-rated health and participant characteristics in the diamond screening 
sample $(\mathrm{N}=7,667)^{41}$ and the diamond baseline sample $(\mathrm{N}=789),{ }^{35}$ and results were reported as odds ratios with 95 percent confidence intervals and $P$ values. Generalized estimating equations with robust standard errors were used to allow for the clustering of patients in practices. ${ }^{42}$ Using backwards elimination stepwise logistic regression, patient characteristics were selected to build the multivariable model if they exhibited a moderate level of association $(P<.1)$ with self-rated health. For participant characteristics highly correlated with each other (eg, long-term illness and multimorbidity), only 1 of the characteristics was included in the multivariable model. ${ }^{23}$

The second stage of analysis (longitudinal analyses) examined whether poor to fair self-rated health was predictive of risk of major depressive syndrome (outcome) at 1, 2, 3, 4, and 5 years (time) from enrolment in the diamond study (baseline), addressing the primary aim of the article. Generalized linear models using generalized estimating equations specifying the identity and $\log$ link functions were used to estimate risk differences and risk ratios, respectively. Robust standard errors were used to adjust for the correlated outcomes of individuals within practices and repeated outcomes measured within individuals. The outcome measured at each year of follow-up was arranged as a single variable, and the time variable identified the year. The model included self-rated health (poor to fair vs good to excellent) and time (treated as a categorical variable) as fixed effects, and it fitted an interaction between self-rated health and time to obtain separate estimates of the parameter at each follow-up year.

Multivariable regression was used to adjust the risk ratio for self-rated health for baseline depression, fitted as either a binary variable or continuous variable, and for potential confounders (sex, age, and multimorbidity).

Prognostic performance was assessed in terms of calibration (difference between predicted and observed rates of $\left.\mathrm{MDS}^{8}\right)$ and discrimination $\left(\mathrm{C}\right.$ stastistics $\left.{ }^{43}\right)$. Calibration refers to how closely the predicted risk of MDS agrees with the observed risk of MDS at each year of follow-up. Discrimination is the ability of a model to differentiate between those participants who do and those who do not experience MDS during the follow-up.

Multiple imputation was used to handle missing data. ${ }^{44}$ Given that the largest percentage of incomplete cases was $46 \%$ at 5 years, 50 data sets were imputed ${ }^{45}$ using the "mi impute mvn" command in Stata 12. The imputation model included all the variables of the multivariable model described above and auxiliary variables correlated with missing responses at followup times, which included measures of socioeconomic status, abuse, and mental and physical health. Continuous variables included in the imputation model were checked for deviations from the normal distribution and skewed variable, and they were transformed to a symmetric distribution. The imputed outcomes were dichotomized using adaptive rounding. ${ }^{46}$ The estimates of the parameters for each imputed data set were combined using Rubin's rules. ${ }^{47}$ Results of the longitudinal analyses are reported as risks of MDS, risk differences, and risk ratios for poor to fair compared with good to excellent self-rated health at 1, 2, 3, 4, and 5 years. Estimates of the risk differences and risk ratios are reported with corresponding $95 \%$ confidence intervals and $P$ values.

Ethics approval was granted by the University of Melbourne's Human Research Ethics Committee (ID 030613X).

\section{RESULTS}

Seven hundred eighty-nine participants who scored 16 or more on the CES-D at screening were recruited into the study. Retention rates ranged from $84 \%$ at 1 year to $66 \%$ at 5 years (Figure 1). Complete baseline data $(\mathrm{N}=789)$ were available for self-rated health, CES-D, PHQ-9, multimorbidity, medication, and demographic variables, such as sex, age, and physician location. Less than $2 \%$ of data was missing on other variables at baseline, except for first episode of depression, which had $9 \%$ (74) of missing values.

At baseline, $41 \%$ (95\% CI, 36\%-45\%) of participants rated their health as poor to fair, and MDS was present in $27 \%$ (95\% CI, 23\%-30\%). For 211 participants with MDS, 130 participants $(62 \%, 95 \%$ CI, 54\%$69 \%)$ rated their health as poor to fair, compared with 192 of 578 participants with no MDS (33\%, 95\% CI, 29\%-38\%). Table 1 shows a comparison of the participants' characteristics by self-rated health at baseline. Poor to fair self-rated health was strongly associated with MDS, long-term illness that limited daily activity, and lower socioeconomic status at baseline. The association between participants' characteristics and selfrated health was similar when examined in the 7,667 participants who took part in the screening phase of the diamond study (details available from the authors).

Tables 2 and 3 report the risks, risk differences, and risk ratios of MDS for poor to fair self-rated health compared with good to excellent at each year of follow-up for the complete case and multiple imputation analyses. Prevalence of MDS ranged from 22\% to $27 \%$ across the 5 years of follow-up using the multiply imputed data. Across the 5 years, risk of MDS ranged between $15 \%$ and 19\% for participants reporting good to excellent health and 34\% and 39\% for those with 
poor to fair health. In comparison, the risks of MDS were lower when estimated using the complete cases. The difference between the estimated risks for the complete cases and the imputed data indicates that multiple imputation corrects for a downward bias in

\section{Figure 1. Flowchart of the diamond study cohort.}

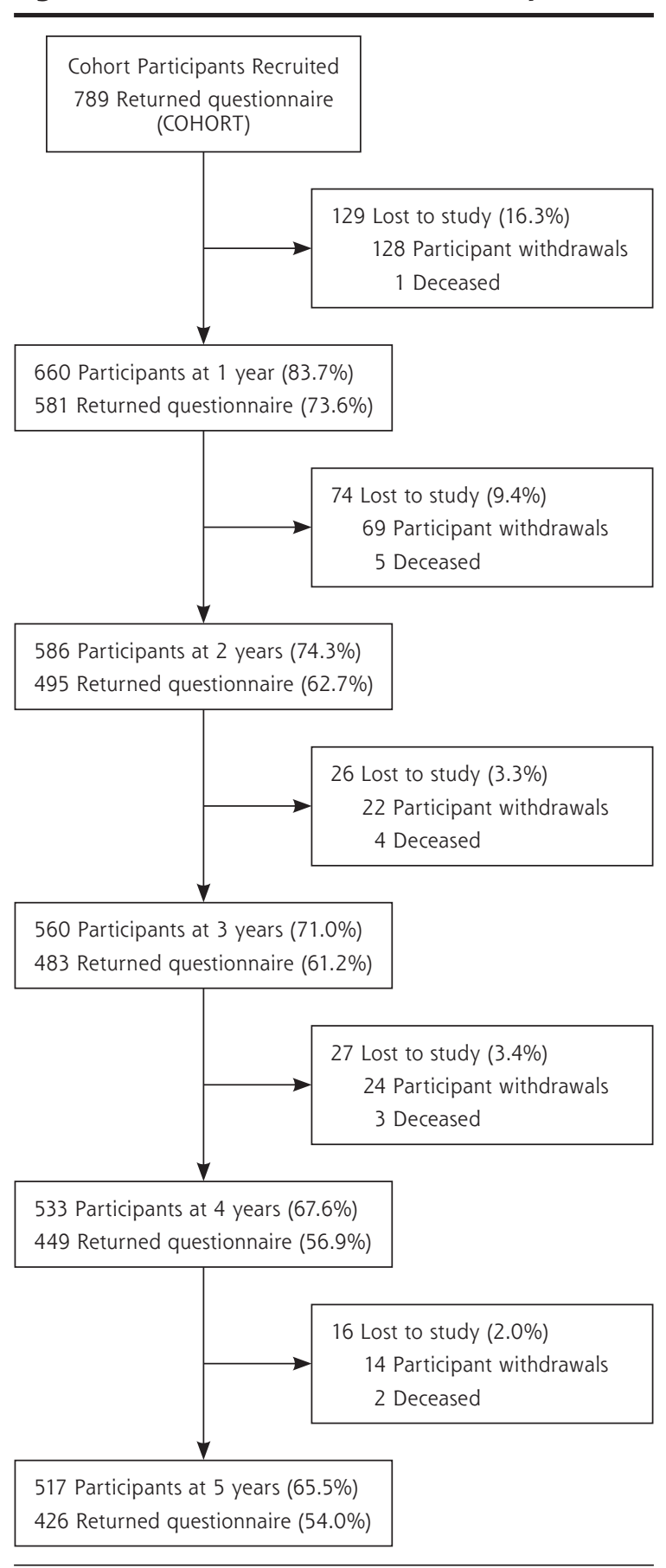

Note: Flowchart of participants who were active in the cohort at each year after they withdrew or died, and the number of active participants that returned the survey questionnaire. the complete-cases estimates, assuming the data are missing at random.

Self-rated health was a strong and consistent predictor of risk of MDS during the 5 years of follow-up. Generally, there was a twofold increase in the risk of MDS for participants rating their health as poor to fair compared with those rating it as good to excellent. Risk differences and risk ratios estimated for the complete cases were more variable over time and estimated with slightly lower precision than those estimated using multiple imputation.

When adjusted for baseline MDS (Table 2), the risk ratios for self-rated health were attenuated, reflecting the positive correlation between self-rated health and MDS at baseline. These risk ratios remained relatively unchanged after adjusting for multimorbidity, age and sex (Supplemental Table). Predicted risks for MDS were lowest for participants rating their health as good to excellent and no MDS at baseline and highest for those with MDS rating their health as poor to fair (Figure 2). Poor to fair self-rated health predicted MDS even when adjusting for depression severity at baseline (Supplemental Table).

When self-rated health was fitted as a single predictor, discrimination was $0.68(95 \% \mathrm{CI}, 0.65-0.70)$ for the complete cases and 0.64 (95\% CI, 0.61-0.66) for the combined multiply imputed data. Differences between observed and estimated risks of MDS were $1 \%$ or less. Discrimination was 0.74 (95\% CI, 0.72 $0.77)$ after adjusting for MDS at baseline; 0.75 (95\% CI, 0.73-0.78) after adjusting for MDS at baseline, multimorbidity, age, and sex; and 0.80 (95\% CI, 0.78 0.82 ) after adjusting for depression severity (complete case analyses).

\section{DISCUSSION}

This study found that self-rated health predicts the risk of future depression in a primary care cohort with depressive symptoms. Compared with those rating their health as good to excellent, those rating their health as poor to fair had a twofold greater risk of MDS up to 5 years later. The association between self-rated health and future depressive status remained strong even after adjusting for age, sex, multimorbidity, and baseline depression status or severity.

These findings build upon a previous study that noted an association between lower levels of self-rated health and future depression in a population-based cohort $^{32}$ and a study of older adults in which self-rated health was found to identify those most at risk of depression. ${ }^{33}$ Participants rating their health as good to excellent had a risk of future depression similar to that of the general primary care patient population, ${ }^{4,48}$ 
Table 1. Participant Sociodemographic, Mental, and Somatic Characteristics by Self-Rated Health Status at Baseline ( $\mathrm{N}=789)$

\begin{tabular}{|c|c|c|c|c|c|c|}
\hline \multirow[b]{3}{*}{ Characteristic } & \multicolumn{2}{|c|}{ Self-Rated Health } & \multicolumn{4}{|c|}{ Association With Self-Rated Health } \\
\hline & \multirow[b]{2}{*}{$\begin{array}{c}\text { Poor/Fair } \\
(\mathrm{N}=322) \text { No. }(\%)\end{array}$} & \multirow[b]{2}{*}{$\begin{array}{c}\text { Good/Excellent } \\
(\mathrm{N}=467) \text { No. }(\%)\end{array}$} & \multicolumn{2}{|l|}{ Univariable $^{a}$} & \multicolumn{2}{|c|}{ Multivariable $^{a}$} \\
\hline & & & OR $(95 \% \mathrm{Cl})$ & $\begin{array}{c}P \\
\text { Value }\end{array}$ & OR $(95 \% \mathrm{Cl})$ & $\begin{array}{c}P \\
\text { Value } \\
\end{array}$ \\
\hline \multicolumn{7}{|l|}{ Demographic } \\
\hline Female & $199(61.8)$ & $364(77.9)$ & $0.46(0.32-0.68)$ & $<.001$ & $0.61(0.40-0.92)$ & .02 \\
\hline \multicolumn{7}{|l|}{ Age, y } \\
\hline $18-34$ & $37(11.5)$ & $103(22.1)$ & Ref & $<.001$ & Ref & .02 \\
\hline $35-54$ & $162(50.3)$ & $237(50.7)$ & $1.87(1.14-3.08)$ & & $2.11(1.22-3.63)$ & \\
\hline $55-76$ & $123(38.2)$ & $127(27.2)$ & $2.63(1.69-4.11)$ & & $1.92(1.15-3.20)$ & \\
\hline \multicolumn{7}{|l|}{ Marital status } \\
\hline Never married & $68(21.3)$ & $116(25.0)$ & Ref & .62 & & \\
\hline Widowed, divorced, separated & $96(30.1)$ & $132(28.4)$ & $1.22(0.82-1.82)$ & & & \\
\hline Married & $155(48.6)$ & $216(46.6)$ & $1.18(0.79-1.78)$ & & & \\
\hline Born in Australia & $270(84.1)$ & $381(81.8)$ & $1.16(0.81-1.67)$ & .42 & & \\
\hline English as first language & $305(94.7)$ & $449(96.6)$ & $0.61(0.29-1.30)$ & .20 & & \\
\hline \multicolumn{7}{|l|}{ Depression-related items } \\
\hline $\begin{array}{l}\text { Major depressive syndrome } \\
\text { (PHQ-9) }\end{array}$ & $130(40.4)$ & $81(17.3)$ & $3.21(2.33-4.43)$ & $<.001$ & $2.54(1.69-3.80)$ & $<.001$ \\
\hline First episode & $94(31.9)$ & $127(30.2)$ & $1.09(0.77-1.54)$ & .63 & & \\
\hline \multicolumn{7}{|l|}{ Medication } \\
\hline $\begin{array}{l}\text { Currently taking depression } \\
\text { medication }\end{array}$ & $160(49.7)$ & $157(33.6)$ & $1.95(1.52-2.49)$ & $<.001$ & & \\
\hline $\begin{array}{l}\text { Currently taking anxiety } \\
\text { medication }\end{array}$ & $34(10.6)$ & $43(9.2)$ & $1.18(0.79-1.77)$ & .42 & & \\
\hline $\begin{array}{l}\text { Currently taking sedative } \\
\text { medication }\end{array}$ & $16(5.0)$ & $14(3.0)$ & $1.74(0.75-4.06)$ & .20 & & \\
\hline $\begin{array}{l}\text { Currently taking antipsychotic } \\
\text { medication }\end{array}$ & $25(7.8)$ & $12(2.6)$ & $3.16(1.61-6.20)$ & .001 & & \\
\hline \multicolumn{7}{|l|}{ Chronic illness items } \\
\hline $\begin{array}{l}\text { Long-term illness limits daily } \\
\text { activity }\end{array}$ & $241(76.8)$ & $164(35.8)$ & $5.86(4.40-7.79)$ & $<.001$ & $3.85(2.78-5.34)$ & $<.001$ \\
\hline Morbidity 2 or more in last 12 mo & $151(46.9)$ & $139(29.8)$ & $2.07(1.48-2.90)$ & $<.001$ & & \\
\hline \multicolumn{7}{|l|}{ Substance abuse } \\
\hline $\begin{array}{l}\text { Alcohol abuse and/or } \\
\text { dependence }\end{array}$ & $44(14.9)$ & $72(16.8)$ & $0.88(0.60-1.29)$ & .50 & & \\
\hline $\begin{array}{l}\text { Substance abuse and/or } \\
\text { dependence }\end{array}$ & $32(10.9)$ & $28(6.5)$ & $1.71(0.97-2.99)$ & .06 & & \\
\hline \multicolumn{7}{|l|}{ SES-related items } \\
\hline \multicolumn{7}{|l|}{ Highest level of education } \\
\hline Completed year 12 or less & $194(60.4)$ & $240(51.5)$ & Ref & .11 & & \\
\hline Certificate or diploma & $73(22.7)$ & $117(25.1)$ & $0.79(0.52-1.20)$ & & & \\
\hline Bachelor degree or higher & $54(16.8)$ & $109(23.4)$ & $0.64(0.42-0.98)$ & & & \\
\hline Benefit as main source of income & $165(51.6)$ & $116(25.2)$ & $3.15(2.46-4.02)$ & $<.001$ & $1.70(1.32-2.20)$ & $<.001$ \\
\hline \multicolumn{7}{|l|}{ Employment status } \\
\hline Employed or student & $144(45.0)$ & $331(71.0)$ & Ref & $<.001$ & Ref & .001 \\
\hline Not employed & $83(25.9)$ & $117(25.1)$ & $1.62(1.08-2.43)$ & & $1.18(0.79-1.77)$ & \\
\hline Unable to work & $93(29.1)$ & $18(3.9)$ & $11.67(7.12-19.13)$ & & $2.24(1.45-3.47)$ & \\
\hline \multicolumn{7}{|l|}{ Manage on available income } \\
\hline Easily, not too bad & $105(32.7)$ & $232(50.0)$ & Ref & $<.001$ & & \\
\hline Difficult some of the time & $117(36.5)$ & $175(37.7)$ & $1.49(1.08-2.06)$ & & & \\
\hline Difficult all of the time & $99(30.8)$ & $57(12.3)$ & $3.85(2.67-5.55)$ & & & \\
\hline General physician rural location & $113(35.1)$ & $136(29.1)$ & $1.33(0.92-1.93)$ & .13 & & \\
\hline
\end{tabular}

OR = odds ratio; ref = reference; $S E S=$ socioeconomic status.

Note: Discrepancies in totals are due to missing responses.

${ }^{a} \mathrm{~N}=761$. Odds ratio, 95\% confidence intervals, and $P$ values calculated using marginal logistic regression using generalized estimating equations with robust standard errors to allow for correlated responses within practices and individuals. 
Table 2. Risks, Risk Differences, and Risk Ratios of Major Depressive Syndrome at 1, 2, 3, 4, and 5 Years for Poor to Fair Compared With Good to Excellent Self-Rated Health: Complete Case Analysis

\begin{tabular}{|c|c|c|c|c|c|c|c|c|c|}
\hline \multirow[b]{2}{*}{ Analysis } & \multicolumn{3}{|c|}{ Poor/Fair SRH } & \multicolumn{3}{|c|}{ Good/Excellent SRH } & \multicolumn{2}{|c|}{ Unadjusted } & \multirow{2}{*}{$\begin{array}{c}\text { Adjusted }^{a} \\
\text { Risk Ratio }^{b} \\
(95 \% \mathrm{Cl})\end{array}$} \\
\hline & $\mathbf{N}$ & $\mathrm{n}$ & $\%$ & $\mathrm{~N}$ & $\mathrm{n}$ & $\%$ & $\begin{array}{l}\text { Risk Difference }^{\mathrm{b}} \\
(95 \% \mathrm{Cl})\end{array}$ & $\begin{array}{l}\text { Risk Ratio }^{b} \\
(95 \% \mathrm{Cl})\end{array}$ & \\
\hline 1 year & 230 & 86 & 37.4 & 350 & 55 & 15.7 & $21.3(15.4-27.1)$ & $2.36(1.78-3.13)$ & $1.81(1.37-2.39)$ \\
\hline 2 years & 191 & 63 & 33.0 & 303 & 32 & 10.6 & $22.1(14.0-30.2)$ & $3.11(2.07-4.68)$ & $2.29(1.53-3.42)$ \\
\hline 3 years & 187 & 63 & 33.7 & 294 & 31 & 10.5 & $22.7(14.5-31.0)$ & $3.20(2.20-4.66)$ & $2.33(1.49-3.62)$ \\
\hline 4 years & 169 & 50 & 29.6 & 277 & 38 & 13.7 & $15.4(7.0-23.9)$ & $2.13(1.46-3.10)$ & $1.50(1.03-2.18)$ \\
\hline 5 years & 163 & 48 & 29.5 & 261 & 25 & 9.6 & $19.7(13.1-26.3)$ & $3.06(2.13-4.41)$ & $2.34(1.57-3.49)$ \\
\hline
\end{tabular}

PHQ-9 = 9-item Physicians' Health Questionnaire; SRH = self-rated health

${ }^{a}$ Adjusted for PHQ-9 major depressive syndrome at baseline.

${ }^{b}$ Calculated with generalized linear models using generalized estimating equations with robust standard errors to allow for correlated responses within practices and individuals.

Table 3. Risks, Risk Differences, and Risk Ratios of Major Depressive Syndrome at 1, 2, 3, 4, and 5 Years for Poor to Fair Compared With Good to Excellent Self-Rated Health: Multiple Imputation Analysis

\begin{tabular}{|c|c|c|c|c|c|}
\hline \multirow[b]{2}{*}{ Analysis } & \multirow[b]{2}{*}{$\begin{array}{c}\text { Poor/Fair SRH } \\
(\mathrm{N}=322) \%\end{array}$} & \multirow[b]{2}{*}{$\begin{array}{c}\text { Good/Excellent SRH } \\
(\mathrm{N}=467) \%\end{array}$} & \multicolumn{2}{|c|}{ Unadjusted } & \multirow{2}{*}{$\begin{array}{c}\text { Adjusted }^{\mathrm{a}} \\
\text { Risk Ratio }^{\mathrm{b}} \\
(95 \% \mathrm{Cl})\end{array}$} \\
\hline & & & $\begin{array}{l}\text { Risk Difference }^{b} \\
(95 \% \mathrm{Cl})\end{array}$ & $\begin{array}{l}\text { Risk Ratiob } \\
(95 \% \mathrm{Cl})\end{array}$ & \\
\hline 1 year & 39.0 & 18.5 & $20.2(13.6-26.8)$ & $2.10(1.60-2.76)$ & $1.67(1.28-2.19)$ \\
\hline 2 years & 35.1 & 14.7 & $20.1(13.2-27.1)$ & $2.38(1.77-3.20)$ & $1.88(1.40-2.53)$ \\
\hline 3 years & 35.5 & 15.9 & $19.3(12.3-26.3)$ & $2.22(1.70-2.89)$ & $1.81(1.36-2.40)$ \\
\hline 4 years & 33.6 & 19.4 & $13.9(6.5-21.3)$ & $1.73(1.30-2.28)$ & $1.37(1.03-1.84)$ \\
\hline 5 years & 34.2 & 15.8 & $18.0(11.1-24.8)$ & $2.15(1.59-2.90)$ & $1.79(1.32-2.42)$ \\
\hline
\end{tabular}

PHQ- = 9-item Patient Health Questionnaire; SRH = self-rated health.

Note: Using 50 imputed data sets.

adjusted for PHQ-9 major depressive syndrome at baseline.

${ }^{\mathrm{b}}$ Calculated with generalized linear models using generalized estimating equations with robust standard errors to allow for correlated responses within practices and individuals.

Figure 2. Predicted risk of major depressive syndrome at 1, 2,3, 4, and 5 years using multiple imputation, by self-rated health and major depressive syndrome categories at baseline $(\mathrm{N}=789)$.

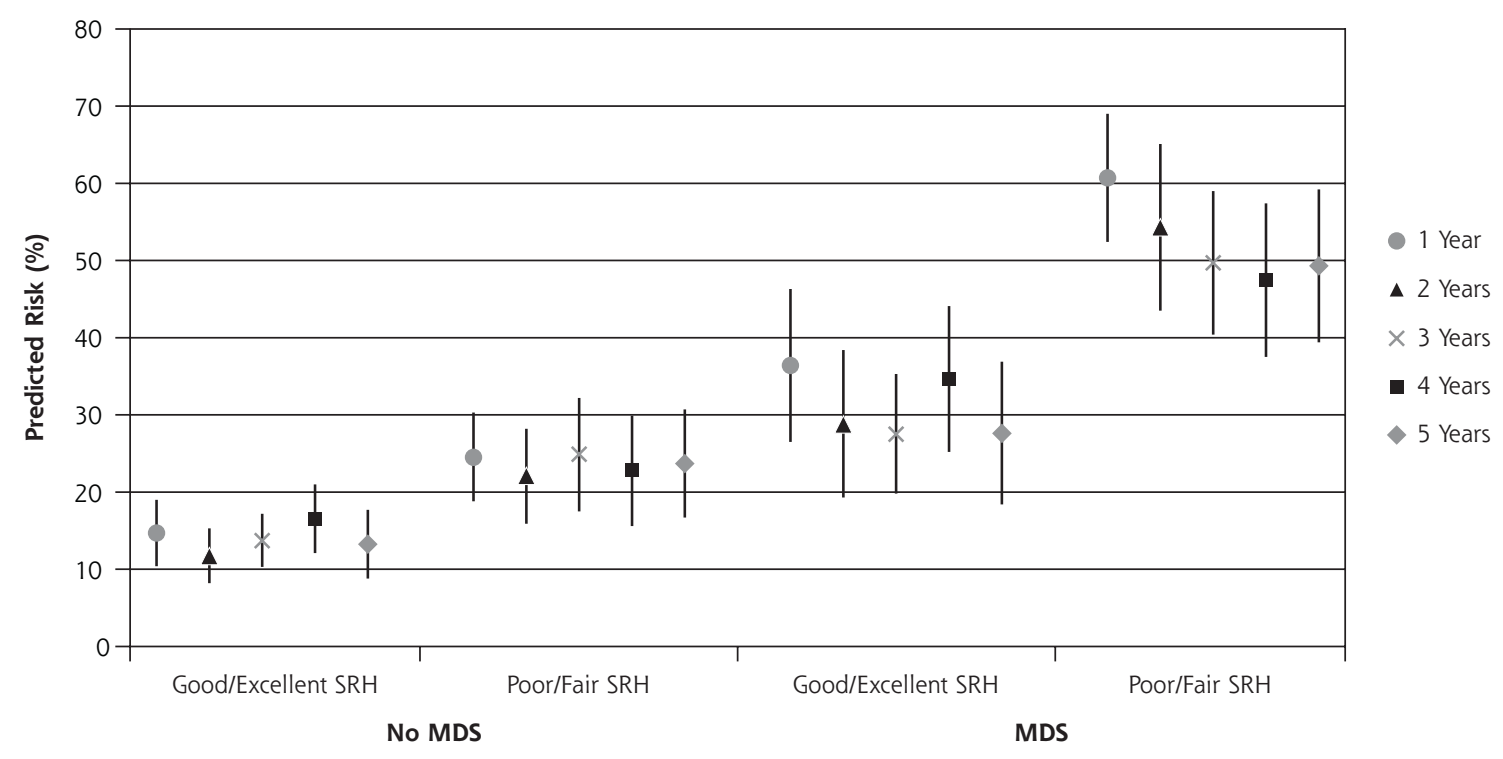

MDS = major depressive syndrome; SRH = self-rated health.

Note: Using 50 imputed data sets. 
whereas those rating their health as poor to fair had a risk of future depression similar to that of the population seen in subspecialty clinics, such as oncology and cardiology. ${ }^{49}$ Rating one's health as poor or fair is a subjective summary measure of health that incorporates disability, depression, and financial difficulties consistent with the findings of Mavadatt et al. ${ }^{26}$ Poor to fair self-rated health may discriminate a subgroup of patients with complex and difficult-to-treat forms of depression complicated by physical ill health and social disadvantage.

Few prognostic tools exist to assist physicians in determining those at increased risk of persistent or recurring depression. One example is the Diagnostic Prognostic Index, developed and validated (in a sample of 1,471 primary care patients with major depression) to predict risk of depression at 6 months. ${ }^{14}$ The Diagnostic Prognostic Index is composed of several items-number of depression symptoms lasting 2 years or more, anxiety symptoms, having completed 3 months of antidepressants at sample entry, common physical symptoms, health interfering with social activities, and social support. The discrimination performance of the single self-rated health question compares reasonably well with the Diagnostic Prognostic Index; based on its quartiles, the calculated discrimination performance using multiple imputation was 0.69 (95\% CI, 0.66-0.72) vs the self-rated health performance of 0.64 (95\% CI, 0.61-0.66). Compared with the Diagnostic Prognostic Index, self-rated health has the advantage of simplicity; it has 1 question vs 7 items. In addition discrimination for self-rated health is stable for 5 years, and its use is applicable in a broader population of patients. When self-rated health and MDS categories are combined, discrimination of the model is $\operatorname{good}^{8}$ and superior to the Diagnostic Prognostic Index.

\section{Strengths}

Longitudinal cohort studies are the best design to answer questions about prognosis. ${ }^{7}$ The diamond cohort is representative of patients with depressive symptoms in Australian primary care ${ }^{35,41}$ and is similar to primary care populations in other developed countries. ${ }^{4}$ This cohort represents the heterogeneous and variable nature of depression seen in primary care. ${ }^{11,14}$ Data are of good quality, with recruitment and attrition rates in the range of those reported in longitudinal studies of depression in primary care. ${ }^{50,51}$ Missing data have been dealt with rigorously using multiple imputation methods to overcome possible biases related to complete case analysis. Depression outcome was assessed with the PHQ-9 diagnostic criteria, which have good levels of agreement with diagnoses of independent mental health professionals. ${ }^{52}$ We have assessed predictive accuracy (ie, discrimination and calibration) as proposed in the current literature on prognosis. ${ }^{8,23,53}$

\section{Limitations}

A single predictor rarely gives an adequate estimate of prognosis ${ }^{7}$ and cannot be considered a prognostic

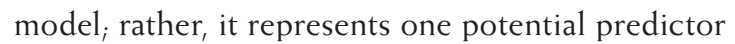
that is easy to implement in primary care. Self-rated health may not be the single best prognostic variable for depression-prone cohorts, and future research could investigate other potential indicators. This study focused on patients with recent experience of depressive symptoms. Further research is needed to determine whether self-rated health successfully predicts outcome beyond the study population. ${ }^{54}$

\section{Implications for Physicians}

Family physicians, who are often the first contact for health care, are required to differentiate a wide range of symptoms from a complex narrative in a short period of time. The goal of prognosis is to improve clinical decision making, and the findings described here have important clinical relevance. Self-rated health provides sufficient prognostic information to indicate long-term increased risk of poor depression outcome for primary care patients with recent experience of depressive symptoms. Simply assessing self-rated health using the single question presented here and assessing depression status using the PHQ-9 (which is widely used in primary $\operatorname{car}^{38}$ ) could fit well within routine clinical care. Such information will provide reliable information about risk of future depression.

Although a prognostic model including self-rated health and depression severity was more accurate, it is more complex to interpret and would require more effort to implement into routine care. Interestingly, the findings suggest that incorporating age, sex, and multimorbidity into the model adds little to the prognostic information provided by assessment of self-rated health and MDS. Accuracy could be increased by building more comprehensive models that include other risk factors for depression based on specific validated questionnaires. There is a trade-off, however, between validity and clinical acceptability of prognostic tools, especially in busy practice. ${ }^{6}$

When a patient with a recent experience of depressive symptoms rates his or her health as poor to fair, it should prompt a thorough biopsychosocial evaluation leading to an intensive and comprehensive treatment plan. Patients with depressive symptoms who report poor to fair self-rated health may benefit from being fast-tracked to proactive follow-up and collaborative care models rather than a stepped-care approach. 
To read or post commentaries in response to this article, see it online at www.annfammed.org/content/12/1/57.

Key words: depression; primary care; prognosis; self-rated health; longitudinal study

Submitted August 16, 2012; submitted, revised, March 29, 2013; accepted April 8, 2013.

Funding support: The diamond study was initiated with pilot funding from the Beyondblue Victorian Centre of Excellence and the main cohort has received project grant funding from the National Health and Medical Research Council (ID 299869, 454463, 566511, and 1002908). The one year Computer Assisted Telephone Interview was funded by a Stream 3 grant from the Australian Primary Health Care Research Institute (APHCRI). Research fellowship of Ambresin was supported by a scholarship from the Centre Hospitalier Universitaire Vaudois and the Department of Psychiatry of the University of Lausanne, Switzerland.

Disclaimer: No funding body had a role in study design; the collection, analysis, and interpretation of data; the preparation, review, or approval of the manuscript; or the decision to submit this manuscript for publication.

diamond Study investigators: Jane M. Gunn, Helen Herrman, Mike Kyrios, Kelsey Hegarty, Christopher Dowrick, Gail Gilchrist, Grant Blashki, Dimity Pond, Patty Chondros, Renata Kokanovic, and Victoria Palmer.

Acknowledgments: We acknowledge the 30 dedicated general practitioners, their patients, and practice staff for making this research possible. We thank the cohort participants for their ongoing involvement in the study. We also thank the diamond project team and associate investigators involved in the study: Lena Sanci, Maria Potiriadis, Konstancja Densley, Aves Middleton, Melanie Charity, and the casual research staff.

Supplementary materials: Available at www.annfammed.org/ content/12/1/57/suppl/DC1/

\section{References}

1. World Health Organization (WHO). The Global Burden of Disease: 2004 Update. Geneva, Switzerland: World Health Organization; 2008.

2. Bloom DE, Cafiero ET, Jané-Llopis E, et al. The Global Economic Burden of Non-communicable Diseases. Geneva, Switzerland: World Economic Forum; 2011.

3. Australian Bureau of Statistics. National Survey of Mental Health and Wellbeing: Summary of Results, 2007. Canberra, Australia; 2007.

4. Herrman H, Patrick DL, Diehr P, et al. Longitudinal investigation of depression outcomes in primary care in six countries: the LIDO study. Functional status, health service use and treatment of people with depressive symptoms. Psychol Med. 2002;32(5):889-902.

5. Cassano P, Fava M. Depression and public health: an overview. J Psychosom Res. 2002;53(4):849-857.

6. Gill TM. The central role of prognosis in clinical decision making. JAMA. 2012;307(2):199-200.

7. Moons KGM, Royston P, Vergouwe Y, Grobbee DE, Altman DG. Prognosis and prognostic research: what, why, and how? BMJ. 2009;338:b375.

8. Yourman LC, Lee SJ, Schonberg MA, Widera EW, Smith AK. Prognostic indices for older adults: a systematic review. JAMA. 2012;307(2):182-192.

9. Van Den Brink RHS, Ormel J, Tiemens BG, et al. Accuracy of general practitioner's prognosis of the 1-year course of depression and generalised anxiety. Br J Psychiatry. 2001;178(1):18-22.
10. van Weel-Baumgarten EM, Schers HJ, van den Bosch WJ, van den Hoogen HJ, Zitman FG. Long-term follow-up of depression among patients in the community and in family practice settings. A systematic review. J Fam Pract. 2000;49(12):1113-1120.

11. Katon W, Unützer J, Russo J. Major depression: the importance of clinical characteristics and treatment response to prognosis. Depress Anxiety. 2010;27(1):19-26.

12. van Beljouw IM, Verhaak PF, Cuijpers $P$, van Marwijk HW, Penninx BW. The course of untreated anxiety and depression, and determinants of poor one-year outcome: a one-year cohort study. BMC Psychiatry. 2010;10:86-86.

13. Colman I, Naicker K, Zeng YY, Ataullahjan A, Senthilselvan A, Patten SB. Predictors of long-term prognosis of depression. CMAJ. 2011;183(17):1969-1976.

14. Rubenstein LV, Rayburn NR, Keeler EB, Ford DE, Rost KM, Sherbourne CD. Predicting outcomes of primary care patients with major depression: development of a depression prognosis index. Psychiatr Serv. 2007;58(8):1049-1056.

15. Simon GE. Long-term prognosis of depression in primary care. Bull World Health Organ. 2000;78(4):439-445.

16. Stegenga BT, Kamphuis MH, King M, Nazareth I, Geerlings MI. The natural course and outcome of major depressive disorder in primary care: the PREDICT-NL study. Soc Psychiatry Psychiatr Epidemiol. 2012:47(1):87-95.

17. Dowrick C, Leydon GM, McBride A, et al. Patients' and doctors' views on depression severity questionnaires incentivised in UK quality and outcomes framework: qualitative study. BMJ. 2009;338:b663.

18. Barley EA, Murray J, Walters P, Tylee A. Managing depression in primary care: A meta-synthesis of qualitative and quantitative research from the UK to identify barriers and facilitators. BMC Fam Pract. 2011;12:47.

19. Kendrick T, Dowrick C, McBride A, et al. Management of depression in UK general practice in relation to scores on depression severity questionnaires: analysis of medical record data. BMJ. 2009;338:b750.

20. Mitchell AJ, Kaar S, Coggan C, Herdman J. Acceptability of common screening methods used to detect distress and related mood disorders-preferences of cancer specialists and non-specialists. Psychooncology. 2008;17(3):226-236.

21. Toner R, Snape C, Acton S, Blenkiron P. Do general practitioners adhere to NICE guidelines for depression? Systematic Questionnaire Survey. Prim Health Care Res Dev. 2010;11(2):123-131.

22. Baik S-Y, Bowers BJ, Oakley LD, Susman JL. The recognition of depression: the primary care clinician's perspective. Ann Fam Med. January 2005;3(1):31-37.

23. Royston P, Moons KGM, Altman DG, Vergouwe Y. Prognosis and prognostic research: Developing a prognostic model. BMJ. 2009; 338:b604.

24. Moons KGM, Altman DG, Vergouwe Y, Royston P. Prognosis and prognostic research: application and impact of prognostic models in clinical practice. BMJ. 2009;338:b606.

25. Ferguson RJ, Robinson AB, Splaine $M$. Use of the reliable change index to evaluate clinical significance in SF-36 outcomes. Qual Life Res. 2002;11(6):509-516.

26. Mavaddat N, Kinmonth AL, Sanderson S, Surtees $P$, Bingham $S$, Khaw KT. What determines Self-Rated Health (SRH)? A crosssectional study of SF-36 health domains in the EPIC-Norfolk cohort. J Epidemiol Community Health. 2011;65(9):800-806.

27. Jerant A, Tancredi DJ, Franks P. Mortality prediction by qualityadjusted life year compatible health measures: findings in a nationally representative US sample. Med Care. 2011;49(5):443-450.

28. Miilunpalo S, Vuori I, Oja P, Pasanen M, Urponen H. Self-rated health status as a health measure: the predictive value of self-reported health status on the use of physician services and on mortality in the working-age population. J Clin Epidemiol. 1997;50(5):517-528. 
29. Goldberg P, Guéguen A, Schmaus A, Nakache J-P, Goldberg M. Longitudinal study of associations between perceived health status and self reported diseases in the French Gazel cohort. J Epidemiol Community Health. 2001;55(4):233-238.

30. Goldney RD, Eckert KA, Hawthorne G, Taylor AW. Changes in the prevalence of major depression in an Australian community sample between 1998 and 2008. Aust N ZJ Psychiatry. 2010;44(10):901-910.

31. Gunn J, Ayton D, Densley K, et al. The association between chronic illness, multimorbidity and depressive symptoms in an Australian primary care cohort. Soc Psychiatry Psychiatr Epidemiol. 2012;47(2): 175-184.

32. Colman I, Ataullahjan A. Life course perspectives on the epidemiology of depression. Can J Psychiatry. 2010;55(10):622-632.

33. Thielke SM, Diehr $P$, Unutzer J. Prevalence, incidence, and persistence of major depressive symptoms in the Cardiovascular Health Study. Aging Ment Health. 2010;14(2):168-176.

34. Radloff LS. The CES-D Scale. Appl Psychol Meas. 1977;1(3):385-401.

35. Gunn JM, Gilchrist GP, Chondros P, et al. Who is identified when screening for depression is undertaken in general practice? Baseline findings from the Diagnosis, Management and Outcomes of Depression in Primary Care (diamond) longitudinal study. Med J Aust. 2008;188(12)(Suppl):S119-S125.

36. Kroenke K, Spitzer RL, Williams JBW. The PHQ-9: validity of a brief depression severity measure. J Gen Intern Med. 2001;16(9):606-613.

37. Arroll B, Goodyear-Smith F, Crengle S, et al. Validation of PHQ-2 and PHQ-9 to screen for major depression in the primary care population. Ann Fam Med. 2010;8(4):348-353.

38. Kroenke K, Spitzer RL. The PHQ-9: A new depression diagnostic and severity measure. Psychiatr Ann. 2002;32(9):509-521.

39. Ware JE Jr, Kosinski M, Keller SD. A 12-Item Short-Form Health Survey: construction of scales and preliminary tests of reliability and validity. Med Care. 1996;34(3):220-233.

40. Sibthorpe B, Anderson I, Cunningham J. Self-assessed health among indigenous Australians: how valid is a global question? Am J Pub Health. 2001;91(10):1660-1663.

41. Potiriadis M, Chondros P, Gilchrist G, Hegarty K, Blashki G, Gunn JM. How do Australian patients rate their general practitioner? A descriptive study using the General Practice Assessment Questionnaire. Med J Aust. 2008;189(4):215-219.
42. Zeger SL, Liang K-Y, Albert PS. Models for longitudinal data: a generalized estimating equation approach. Biometrics. 1988:44(4):10491060.

43. Hanley JA, McNeil BJ. The meaning and use of the area under a receiver operating characteristic (ROC) curve. Radiology. 1982; 143(1):29-36.

44. Sterne JAC, White IR, Carlin JB, et al. Multiple imputation for missing data in epidemiological and clinical research: potential and pitfalls. BMJ. 2009;338(7712):b2393.

45. White IR, Royston P, Wood AM. Multiple imputation using chained equations: Issues and guidance for practice. Stat Med. 2011;30(4): 377-399.

46. Bernaards CA, Belin TR, Schafer JL. Robustness of a multivariate normal approximation for imputation of incomplete binary data. Stat Med. 2007;26(6):1368-1382.

47. Rubin DB. Multiple Imputation for Nonresponse in Surveys. New York, NY: J. Wiley \& Sons; 1987.

48. Mitchell AJ, Vaze A, Rao S. Clinical diagnosis of depression in primary care: a meta-analysis. Lancet. 2009;374(9690):609-619.

49. Elliott RL. Depression in primary care. Ethn Dis. 2007;17(2 Suppl 2): S2-28-33.

50. Lamers F, Hoogendoorn AW, Smit JH, et al. Sociodemographic and psychiatric determinants of attrition in the Netherlands Study of Depression and Anxiety (NESDA). Compr Psychiatry. 2012;53(1):63-70.

51. Bellón JA, de Dios Luna J, Moreno B, et al. Psychosocial and sociodemographic predictors of attrition in a longitudinal study of major depression in primary care: the predictD-Spain study. J Epidemiol Community Health. 2010;64(10):874-884.

52. Spitzer RL, Kroenke K, Williams JBW. Validation and utility of a self-report version of PRIME-MD: the PHQ primary care study. Primary Care Evaluation of Mental Disorders. Patient Health Q. JAMA. 1999;282(18):1737-1744.

53. Altman DG, Royston P. What do we mean by validating a prognostic model? Stat Med. 2000;19(4):453-473.

54. Altman DG, Vergouwe $Y$, Royston P, Moons KGM. Prognosis and prognostic research: validating a prognostic model. BMJ. 2009;338: b605. 